\title{
Barreneche, Osvaldo. De brava a dura. Policía de la Provincia de Buenos Aires. Una historia (1930-1973). Rosario, Prohistoria Ediciones, 2019, 176 p
}

Acaso el epílogo de este libro sea un buen punto de partida para esta reseña. Las reflexiones que desarrolla allí Osvaldo Barreneche, recorren de algún modo toda la obra y reúnen parte de las preocupaciones centrales que atraviesan actualmente los estudios históricos de policía. En esas líneas finales, el autor esgrime una suerte de balance de lo avanzado en el campo de estudios policiales en los últimos años y diseña una agenda de pendientes. A su vez, se adentra en el análisis de las dificultades para construir un objeto de estudio de legitimidad académica, en la vacancia de estudios en períodos escasamente explorados y el problema de archivos poco visitados, así como en la necesidad de nutrir un diálogo interdisciplinario más activo en el que los aportes desde la historia, para que contribuyan a la definición de una agenda de políticas públicas en materia de seguridad. Mas allá de la particularidad del contenido y del período que se ocupa el libro, enfocado en el proceso de transformación y profesionalización de la policía de la provincia de Buenos Aires entre los años 1930 y 1973, gran parte del trasfondo de las cuestiones que aquí se abordan, podrían perfectamente pensarse para otros casos y períodos. Quizás el hecho de que esta publicación sea el resultado de años de trabajo de Barreneche, así como cada una de sus partes el reflejo de puntos de arribo en su investigación sobre momentos puntuales de esa historia, explique la idea de que es una contribución para pensar sobre los estudios de policía en general y no solo sobre su experiencia bonaerense. Las reflexiones manifestadas en el libro en torno a la génesis de las reformas policiales, la construcción de la idea e identidad de la familia policial o el interrogante (así como la percepción de incomodidad que genera) en torno a la condición del policía cómo trabajador, exceden con evidencia la experiencia bonaerense y se colocan en el nutrido universo de indagaciones en torno a los procesos de construcción de las historias policiales que se desarrollan en la actualidad.

Organizado en cinco capítulos, epílogo y un anexo sobre archivos el libro se construye sobre la idea de un proceso de transformación de una policía brava, cimentada sobre las particularidades institucionales adquiridas de los rasgos políticos y sociales de los años treinta, hacia una policía dura de los años setenta y antecedente inmediato de los años de la escalada represiva de la última dictadura militar en Argentina. En el largo período escogido por el autor para el desarrollo de su libro - y del que demuestra un gran conocimiento de los rasgos de su objeto de estudio- el planteo que formula se sostiene sobre cinco problemas y experiencias históricas específicas recortadas en diferentes temporalidades.

Así, en su primer capítulo Reformas Permanentes, se adentra en un tema constitutivo de las historias de las instituciones de policía vinculado a sus momentos de reforma y su asociación a circunstancias de crisis en las que, una suma de factores pone en marcha puertas adentro de la institución, la maquinaria transformadora con la finalidad de anular aspectos negativos que tienen su correlato en la impugnación social. La primer reforma analizada, hace foco sobre aquella policía brava de los años treinta afianzada sobre un territorio fragmentado en lealtades políticas y vínculos locales en la que primaban vicios y corrupción. No obstante, el logro reformista se basó en el objetivo común de articular la persecución ideológica y 
represión del comunismo, dónde la policía tendría un rol central en la recolección de información y vigilancia que se ampliará notablemente en la década siguiente. El segundo momento que se analiza es, durante la jefatura de Adolfo Marsillach, en el marco de la gobernación de Domingo Mercante, en el que la reforma adquiere un carácter fundacional y se identifica con los postulados del peronismo. La implementación de un orden, centralización y doctrina de inspiración militar con un sistemático crecimiento en la compilación de información de actividades políticas, sindicales y estudiantiles, ubicó a la policía en un rol clave para la represión de individuos y sectores antiperonistas. En los años siguientes, en el cambiante contexto político de purga y desperonización de mediados de los años cincuenta - y al amparo del plan Conintes - se impulsó una reforma de desdoblamiento de fuerzas y formación de grupos operativos especiales. Afirma Barreneche que, bajo la coordinación militar se facultó la cooperación policial con las Fuerzas Armadas para la persecución y represión política que tuvo continuidad en los grupos de tareas de la década siguiente. Esa experiencia generó también una suerte de pertenencia administrativa extraordinaria, y autónoma de las diferentes jefaturas que como un hilo conducente confluirá en la experiencia política de los años setenta.

En Los orígenes de la familia policial, el autor rastrea, el nacimiento de una identidad de pertenencia colectiva a la policía provincial, fundada inicialmente en realidades comunes (salarios, beneficios sociales, estabilidad) y que, confluyeron en la construcción de espacios que fueron delineando valores, idearios y prácticas propias. Abre así, el análisis de una serie de experiencias históricas como fueron la fundación de la Sociedad de Socorros Mutuos, la construcción del Panteón Policial o la conformación de centros de formación profesional que modelaron la noción de "familia policial". Sin duda, este tema instala un universo de tramas más complejas que aventura un trato más exhaustivo y la incorporación de otras fuentes, documentos y voces de actores múltiples.

El tercer capítulo Justicia por mano propia, lo dedica a la experiencia histórica en la que se implementó la justicia policial en la Provincia de Buenos Aires. Aquí Barreneche sorprende con un tema novedoso basado en la implementación de un Código de Justicia Policial que, establecía un fuero propio hasta ese momento exclusivo para militares. Enmarcado en el contexto político de los años finales del gobierno de Perón, en los que la desconfianza justamente en el respaldo militar reforzó la necesidad de sostener el apoyo y lealtad de las fuerzas policiales. El otorgamiento de un fuero especial como instrumento para el juzgamiento de delitos comunes - incluyó un polémico artículo para los casos caratulados como de "legítima defensa"- se hizo realidad, en una fase madura del proceso de profesionalización y en un momento político particular que, generó un mensaje fuerte hacia adentro de la propia fuerza. Esa experiencia breve pero significativa de justicia endogámica contribuyó, según Barreneche, a una concepción de policía dura, parte fundamental del núcleo ideológico de esa policía en la segunda mitad del siglo XX. Sin duda, como el propio autor reconoce, este innovador tema y el análisis de los novedosos expedientes trabajados allí, amerita continuar la indagación hacia otras miradas y registros de esa experiencia histórica.

El capítulo Corrupción y violencia, se propone indagar sobre la génesis e incremento de las prácticas de violencia policial posteriores a 1955 con el análisis de la escalada de detenciones, torturas y abusos policiales perpetuados en el espacio de las comisarias bonaerenses. Proceso complementado con el creciente avance de la corrupción, vinculado al juego y la prostitución que, con aval de autoridades policiales, políticas y judiciales, tuvo un débil impacto en procesos judiciales de bajas condenas y nulidad o desestimación de denuncias. Así Barreneche, propone examinar estos casos en tanto reflexión sobre la violencia, y pensarlo como problema de estudio específico refractario de la reconfiguración organizacional de las policías en la segunda mitad del siglo.

En su último capítulo Las y los policías como trabajadores, el autor encara un tema necesario y complejo para el enfoque de los estudios policiales. Partiendo del análisis de las demandas y reclamos históricos por equiparación salarial, la ampliación de la cobertura social o un mayor reconocimiento profesional que se mantuvo por décadas en la policía provincial, se pregunta por la condición de los policías en tanto trabajadores, las reivindicaciones por la mejora en las condiciones de trabajo y los derechos de organización. El capítulo incluye, el original análisis de la inédita huelga policial de marzo de 1973 y el surgimiento de un 
movimiento policial (Mopol) que perdurará justamente como referente de las reivindicaciones laborales. Sin embargo, estos escasos antecedentes no generaron un gran debate al respecto, y más bien, ha perdurado la incomodidad de su tratamiento y una atención esquiva del mismo. Barreneche sugiere que la deuda de una reflexión profunda sobre la condición de los policías como trabajadores y de su derecho a sindicalización, puede nutrirse del aporte de la investigación histórica y contribuir al diseño de políticas de derechos. La inclusión de este capitulo final en el libro va en ese sentido y lo instala inexorablemente en la agenda de futuras investigaciones.

Finalmente, el libro cierra con un Anexo dedicado al problema de los Archivos policiales y la investigación histórica, si bien, orientado a los archivos provinciales en particular, da cuenta de las problemáticas que atraviesa sin duda toda empresa de investigación y la vinculación al acceso, los alcances y limitaciones de estos.

De brava a dura, confirma nuevamente el lugar de referencia que ocupa Osvaldo Barreneche para los estudios de policía. El despliegue de temas y conocimiento de documentos policiales, la identificación de temáticas innovadoras, así como la sutileza para la interpretación de procesos internos de la cultura policial, avalan esta afirmación y conforman un aporte potente al activo escenario que despliega en la actualidad el campo de investigaciones.

CC BY-NC-SA 